\title{
Comparative Stability Analysis of Boron Nitride Nanotube using MD Simulation and Nonlocal Elasticity Theory
}

\author{
Kadir Mercan ${ }^{a *}, \ddot{O}_{m e r}$ Civalek $^{b}$ \\ ${ }^{a}$ Department of Civil Engineering, Faculty of Architecture-Engineering, Burdur Mehmet Akif Ersoy University \\ ${ }^{b}$ Research Center for Interneural Computing University, China Medical University, Taichung, Taiwan \\ ${ }^{*}$ E-mail address: kmercan@mehmetakif.edu.tr ${ }^{\mathrm{a}^{*}}$, civalek@yahoo.com $^{\mathrm{b}}$
}

ORCID numbers of authors:

0000-0003-3657-6274 ${ }^{*}$, 0000-0003-1907-9479

Received date: 24.12 .2021

Accepted date: 31.12 .2021

\begin{abstract}
Boron Nitride Nanotube (BNNT) is a promising nano sized structure with superior electrical, physical, and mechanical properties comparing to Carbon nanotube. Higher Young's modulus, oxidation resistance, hardness, corrosion resistance, durability in high temperature, piezoelectric and pyroelectric characteristics are some featured characteristics of BNNT. In this paper the critical buckling load of Boron Nitride Nanotube is investigated. Two different method is used. First Eringen's nonlocal elasticity theory is employed to obtain sizedependent critical buckling loads. Then, LAMMPS software is used to simulate molecular dynamics and obtain critical buckling loads. Zigzag (5,5) BNNT with 400 atoms is examined into MD simulation analyzes.
\end{abstract}

Keywords: BNNT, Nonlocal Elasticity Theory, LAMMPS, MD Simulation.

\section{Introduction}

Since more than a decade, nanoscience has gained much popularity parallel to advances in technology and shrink in size of electronic devices. Starting from 1991 by Iijima's discovery of carbon nanotube (CNT) [1], the interest to nanotubes and nano sized structures increased substantially. CNT was the first discovered nanotube and attracted great attention [2], but this outstanding nano sized material had some weak properties comparing to discovered and developed nanotubes and nano sized materials latterly. The main reason to the substantial increase in the interest and usage of nanomaterials was the extreme mechanical, electrical, and thermal properties of materials comparing to conventional materials used while these materials emerged around thirty years ago. Boron Nitride Nanotube (BNNT), Silicon Carbide Nanotube (SiCNT) are some newer types of nanotube with some advantages and disadvantages compared to CNT [3]. Comparing the mechanical properties of these three types of nanotube by checking its Young's modulus BNNT become prominent with $1.8 \mathrm{TPa}$ while CNT perform $1 \mathrm{TPa}$, and SiCNT around $0.62 \mathrm{TPa}[4,5]$. BNNT has a wide usage area since their superior electrical and mechanical properties and physical properties. Ferreira et al. investigated the BNNT's drug delivery capacity as nanovectors to kill cancer cells using magnetohyperthermia therapy by targeting nanbotubes to tumor areas. Results demonstrated that magnetite nanoparticles are linked to the nanotubes while coercivity and magnetization were stable after fusion to nanotube [6]. Khaleghian and Azarakhshi studied $(9,9)$ BNNT's quantum mechanical investigation of 
geometrical structure and dynamic behavior [7]. Vedaei and Nadimi studied the gas sensing properties of $\mathrm{BNNT}$ toward $\mathrm{NO}_{2}, \mathrm{O}_{2}$ and $\mathrm{H}_{2} \mathrm{O}$ [8]. Ashraf et al. demonstrated the catalytic capabilities Cr-BNNT to oxidation of CN molecule [9]. Li et al. analized the stability of MoS2 sheet under uniaxial compression using MD simulation [10]. Yang et al. studied the critical fracture properties of arsene using MD simulation [11]. Jiang et al. studied the stability of blue phosphorus nanotube using MD simulation [12]. Also, Ajori et al. used MD simulation technique to study the buckling behavior x-graphyne based single- and multi-walled nanotubes [13]. More recently, Zhang and Zhou studied the buckling behavior of boron nanotube which compose only from boron atoms[14]. To analyze nanotubes by taking the size effect into consideration, many methods have been used such as couple stress theory $[15,16]$, strain gradient theory, nonlocal elasticity theory [17-22], surface elasticity theory, nonlocal surface elasticity theory [23], DSC method [24-29]. Furthermore, many research have been done studying vibration behavior of nanostructures [30-33].

\section{Boron Nitride Nanotube (BNNT)}

Boron Nitride Nanotube (BNNT) is not the first nanotube discovered but it is one of the most promising with superior electrical, mechanical and physical properties compared to CNT. The structure of Boron Nitride sheet is demonstrated in Figure 1. In Figure 1, blue spheres represent Boron atoms while anthracite spheres represent Nitrogen atoms. Boron and Nitrogen atoms are bonded each other in hexagonal form.

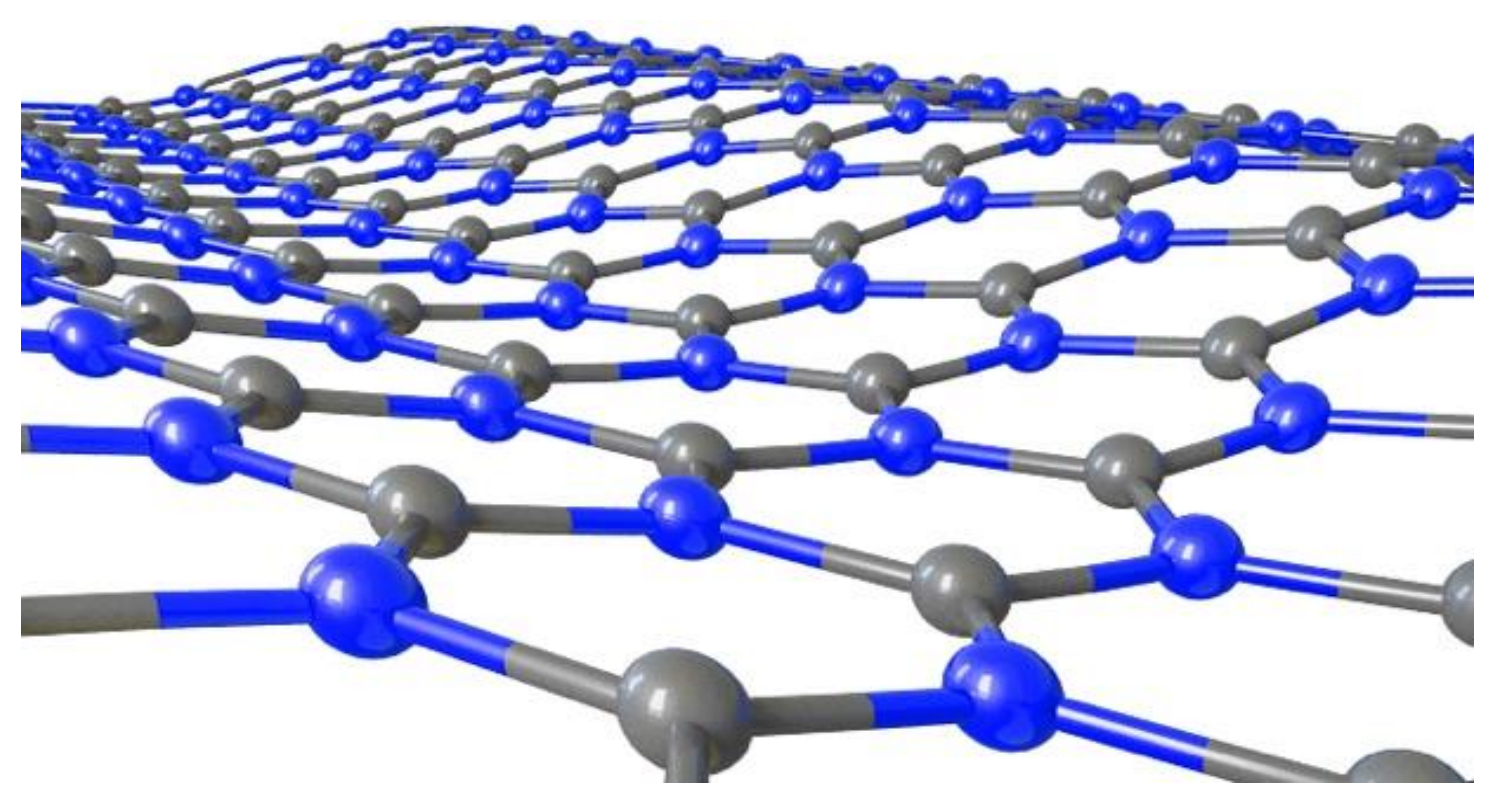

Fig. 1. Structure of Boron Nitride Sheet

BNNTs can be obtained simply by rolling Boron Nitride sheets as it is demonstrated in Figure 2. The rolling side of nanosheet determine the armchair, zigzag, and chiral structure of nanotube [34]. 


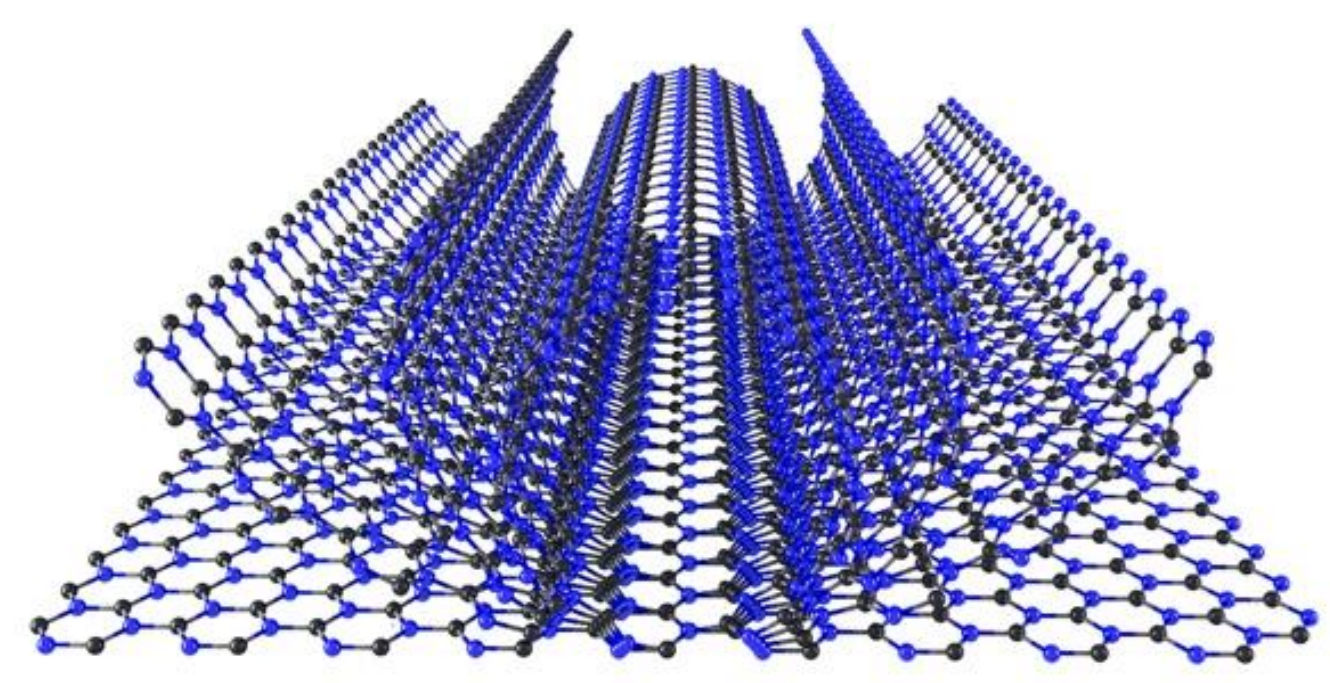

Fig. 2. Rolling Boron Nitride sheet to obtain Boron Nitride Nanotube
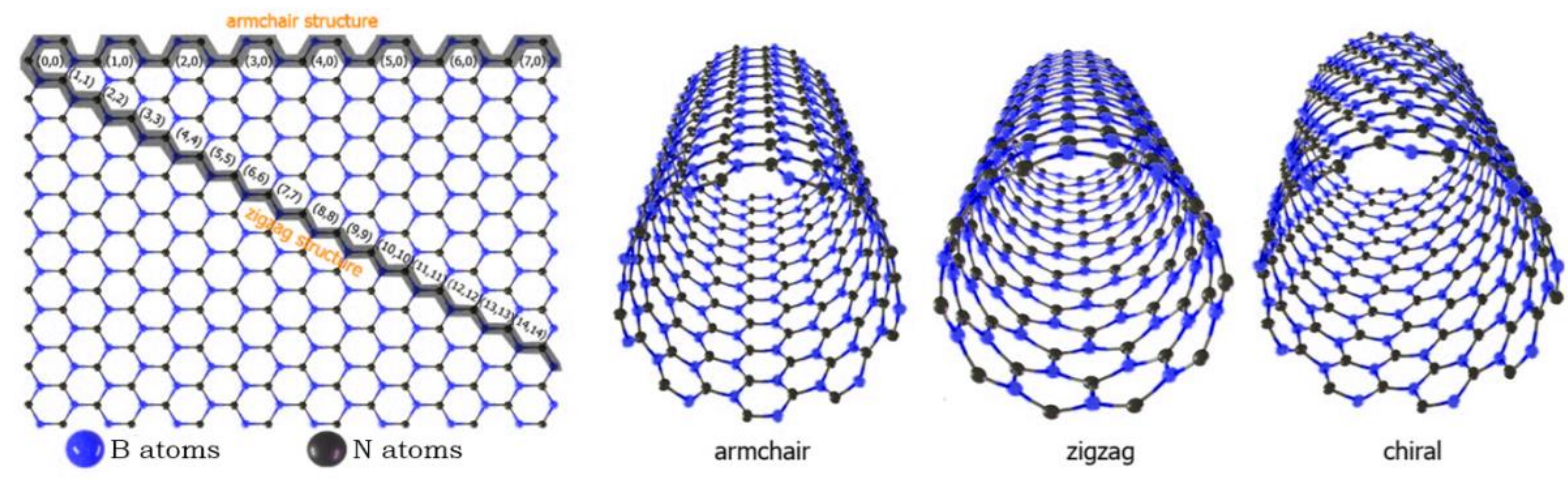

Fig. 3. Armchair, zigzag, and chiral Boron Nitride Nanotube

As it can be seen from Fig. (3) (m, n) represent the zigzag and armchair atom numbers. The rolling side of nanosheet determine the structure of nanotube. Armchair, zigzag, and chiral nanotubes have different physical, mechanical, and electrical properties which are neglected in continuum mechanic. On the other hand, these different properties are taken into consideration in MD simulation methods.

\section{Nonlocal Elasticity Theory for Nanotubes}

Due to the size in nanometer scale in nanotubes, classical continuum mechanic theories perform insufficient in very small sized analyzes. In this paper, Eringen's nonlocal theory is used to take the size effect into consideration [35]. The nonlocal constitutive formulation is [36] 


$$
\left[1-\left(e_{0} a\right)^{2} \nabla^{2}\right] \sigma_{i j}=C_{i j k l}
$$

Where $\sigma_{i j}$ represent the nonlocal stress tensor, $C_{i j k l}\left(x^{\prime}\right)$ is the classical (Cauchy) or local stress tensor at any $x^{\prime}$ point in the body. $e_{0} a$ is the nonlocal parameter constant which depends on the material used in a range. Displacement components of a Euler-Bernoulli beam theory can be represented as

$$
\begin{aligned}
& u_{1}(x, z)=-z \frac{\mathrm{d} w(x)}{\mathrm{d} x} \\
& u_{2}(x, z)=0 \\
& u_{3}(x, z)=w(x)
\end{aligned}
$$

In above equations $u_{1}, u_{2}, u_{3}$ are the $x-, y-$ and $z-$ of the displacement vector components for $\mathrm{x}, \mathrm{y}, \mathrm{z}$ axes respectively. $w$ is the transverse displacements. The strain-displacement equations can be stated as [37]

$$
\varepsilon_{11}=\frac{d u}{d x}=-z \frac{d^{2} w}{d x^{2}}, \varepsilon_{22}=\varepsilon_{33}=\varepsilon_{12}=\varepsilon_{13}=\varepsilon_{23}=0
$$

In Eq.(5) $\varepsilon_{11}$ represent the axial strain. The stress-strain equations can be expressed as

$$
\sigma_{11}=-E z \frac{d^{2} w}{d x^{2}}, \sigma_{22}=\sigma_{33}=\tau_{12}=\tau_{13}=\tau_{23}=0
$$

According to Eqs. (2-4), the nonlocal stress-strain equations

$$
\sigma_{11}-\mu \frac{d^{2} \sigma_{11}}{d x^{2}}=E \varepsilon_{11}, \sigma_{22}=0, \sigma_{33}=0 \text { and } \tau_{12}=\tau_{21}=0, \tau_{13}=\tau_{31}=0, \tau_{23}=\tau_{32}=0
$$

Minimum total potential energy principle is used to derive governing equations.

$$
\begin{gathered}
\delta \prod=\delta U-\delta W=0 \\
\delta U=\int_{0}^{L} \int_{A}\left(\sigma_{11} \delta \varepsilon_{11}\right) d A d x=\int_{0}^{L} \int_{A}\left(\sigma_{11}\left(-z \frac{d^{2} \delta w}{d x^{2}}\right)\right) d A d x
\end{gathered}
$$

Where $\delta U$ is strain energy. The work can expressed as follows:

$$
\delta W=\int_{0}^{L}\left(P \frac{d w}{d x} \delta \frac{d w}{d x}+q w(x)\right) d x
$$




$$
\int_{0}^{L}\left(-M \frac{d^{2} \delta w}{d x^{2}}\right) d x-\int_{0}^{L}\left(P \frac{d w}{d x} \delta \frac{d w}{d x}+q w(x)\right) d x=0
$$

Where $P$ is axial force. The buckling equation and boundary conditions can be expressed as

$$
\begin{aligned}
& \delta \mathrm{w}: \frac{d w}{d x}\left(P \frac{d w}{d x}\right)-q=\frac{d^{2} M}{d x^{2}} \\
& \frac{d M}{d x}-P \frac{d w}{d x}=0 \text { and } M=0 \\
& M-\mu \frac{d^{2} M}{d x^{2}}=-E I \frac{d^{2} w}{d x^{2}}
\end{aligned}
$$

Substituting Eq. (12) into Eq. (14), the moment resultant can be obtained as follows

$$
\begin{gathered}
M=\mu\left(\frac{d}{d x}\left(P \frac{d w}{d x}\right)-q\right)-E I \frac{d^{2} w}{d x^{2}} \\
\delta \mathrm{w}: \frac{d^{2}}{d x^{2}}\left(-E I \frac{d^{2} w}{d x^{2}}\right)+\mu \frac{d^{2}}{d x^{2}}\left(\frac{d}{d x}\left(P \frac{d w}{d x}\right)-q\right)+q-\frac{d}{d x}\left(P \frac{d w}{d x}\right)=0
\end{gathered}
$$

Nonlocal boundary conditions are as follows [23]

$$
\begin{gathered}
\frac{d}{d x}\left(\mu\left(\frac{d}{d x}\left(P \frac{d w}{d x}\right)-q\right)-E I \frac{d^{2} w}{d x^{2}}\right)-P \frac{d w}{d x}=0 \\
\mu\left(\frac{d}{d x}\left(P \frac{d w}{d x}\right)-q\right)-E I \frac{d^{2} w}{d x^{2}}=0
\end{gathered}
$$

For a nanobeam resting on double parameter Pasternak foundation

$$
p(x)=k_{w} w-k_{p} \frac{d^{2} w}{d x^{2}}
$$

In Eq. (19) $k_{w}$ and $k_{p}$ stand for double parameter foundation constants [38]. Subscript w and p represent Winkler and Pasternak respectively. By taking these two constant zero, the foundation effect would be neglected [39]. $\mu$ is the nonlocal parameter.

$$
\left(-E I+P \mu-k_{p} \mu\right) \frac{d^{4} w}{d x^{2}}+\left(k_{w} \mu-P+k_{p}\right) \frac{d^{2} w}{d x^{2}}-k_{w} w=0
$$

The critical buckling load for a nanobeam resting on two parameter foundation including nonlocal size effect can be stated as follows: 


$$
P(n)=\frac{\left(\overline{E I}-k_{p} \mu\right)\left(\frac{n \pi}{L}\right)^{4}+\left(k_{w} \mu+k_{p}\right)\left(\frac{n \pi}{L}\right)^{2}+k_{w}}{\mu\left(\frac{n \pi}{L}\right)^{4}+\left(\frac{n \pi}{L}\right)^{2}}
$$

The real view and its continuum model of BNNT is demonstrated in Fig. 4. As it can be seen from the bottom of Fig. 4 the continuum model of BNNT have no structural details. Modeled structure can be seen as a standard tube. The effect of armchair, zigzag, or chiral structure can be defined to the model only by determining the material properties differently.
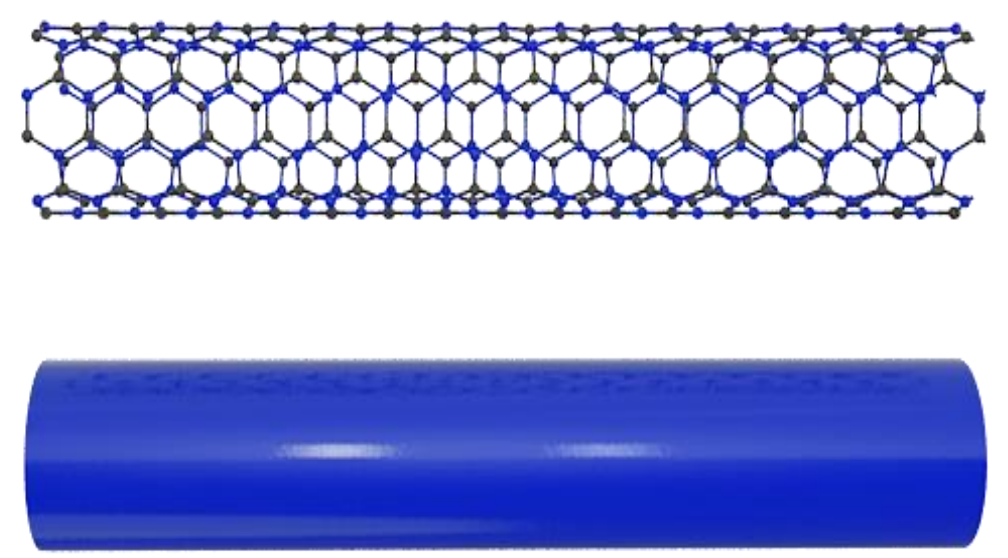

Fig. 4. Real view (top) and continuum model (bottom) of BNNT

\section{Molecular Dynamics for Nanotubes}

Zigzag, armchair, and chiral structures details of nanotube have key role on molecular dynamic simulation. The chiral indices of nanotube are represented as $(m, n)$. In this paper the chiral structure of BNNT is analyzed. Modeling the structure for MD simulation was done using Visual Molecular Dynamics (VMD). After modeling the structure, obtained data is implemented to LAMMPS software [40]. LAMMPS is commonly used to simulate the molecular dynamics and perform interactions between objects. Hence Tersoff potential is used to model the intercommunication between atoms of BNNT structure [41-44].

$$
2 E=\sum_{i} \quad \sum_{j \neq 1} f_{c}\left(r_{i j}\right) \quad\left(f_{T}\left(r_{i j}\right)+b_{i j} f_{E}\left(r_{i j}\right)\right)
$$

Where

$$
\begin{aligned}
& f_{T}(r)=A e^{\left(-\lambda_{1} r\right)} \\
& f_{E}(r)=-B e^{\left(-\lambda_{2} r\right)}
\end{aligned}
$$




$$
\begin{array}{cc}
1 & \begin{array}{c}
1 \\
f_{C}(r)=0.5-0.5 \sin \left(\frac{\pi}{2}\left(\frac{r-D}{D}\right)\right)
\end{array} \\
0 & : R-D<r<R+D \\
b_{i j}=\sqrt[2 n]{\frac{1}{1+\beta^{n} \xi_{i j}^{n}}} & : r>R+D \\
\xi_{i j}=\sum_{k \neq i, j} f_{C}\left(r_{i j}\right) g\left(\theta_{i j k}\right) e^{\lambda_{3}^{m}\left(r_{i j}-r_{i k}\right)^{m}} \\
g(\theta)=\gamma_{i j k}\left(1+\frac{c^{2}}{d^{2}}-\frac{c^{2}}{d^{2}+\left(\cos \theta-\cos \theta_{0}\right)^{2}}\right)
\end{array}
$$

In above equations $\mathrm{i}, \mathrm{j}$ and $\mathrm{k}$ represent the atom numbers, $\theta$ is the angle between atoms, $r$ is the distance between Boron and Nitrogen atoms. Moreover, $f_{T}$ act in place of a two-body term, $f_{C}$ represent cutoff term while $f_{E}$ stand for three-body interactions.

\section{Numerical Results}

In this section the comparative buckling analysis of BNNT using Eringen's nonlocal elasticity theory and MD simulation is presented. Zigzag $(5,5)$ BNNT is examined with 400 atoms. The length and diameter of nanotube is variable with ratio from 0 to 0.1 . Size dependent continuum mechanic results in harmony with our previous studies [45-56] and MD simulation results.

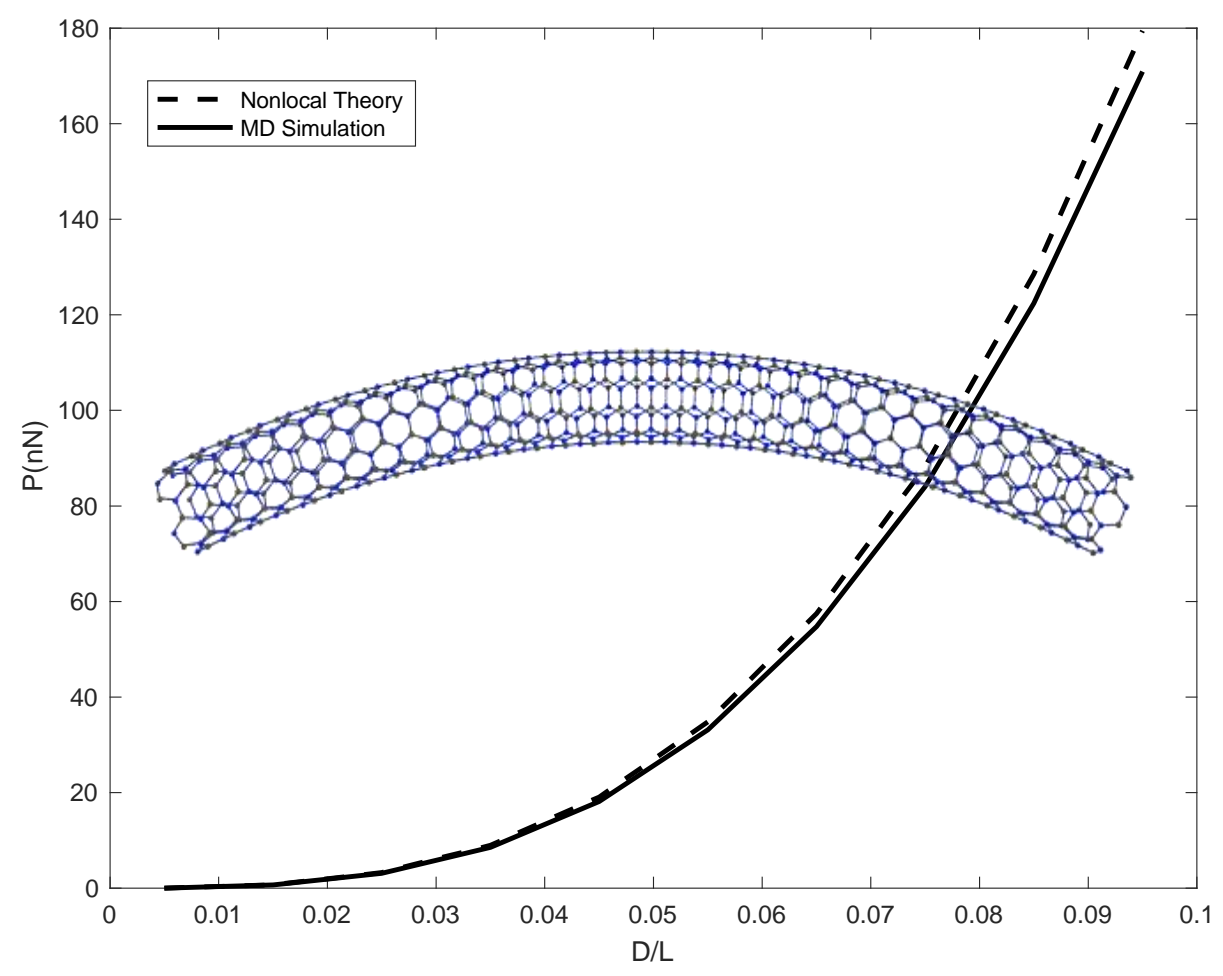

Fig. 5. Critical buckling load of BNNT 
As it is seen from Figure 5, the critical buckling load of BNNT rise with increase in diameter to length ratio. The buckled form of BNNT is demonstrated in Fig. (5). As the critical buckling load is investigated, mode number $\mathrm{n}$ is equal to 1 .

\section{Conclusions}

Boron Nitride Nanotube (BNNT) come forward in the great variety of nanotubes with higher mechanical resistance, oxidation resistance, hardness, corrosion resistance, durability in high temperature, piezoelectric and pyroelectric. The critical buckling load of Boron Nitride Nanotube is investigated using two different methods. Eringen's nonlocal elasticity theory is employed to obtain size-dependent critical buckling loads. LAMMPS software is used to simulate molecular dynamics. The length and diameter of nanotube is selected with ratio from 0 to 0.1 . For lower D/L ratio, the critical buckling load stay low while the critical buckling load get dramatically higher for high $\mathrm{D} / \mathrm{L}$ ratio. To conclude, $\mathrm{MD}$ simulation perform better in case of stability comparing to size-effective continuum mechanic as MD simulation has the opportunity to model and simulate imperfect nanotubes with different properties.

\section{References}

[1] Iijima, S., Helical microtubules of graphitic carbon. Nature, 354(6348), 56, 1991.

[2] Demir, C., Mercan, K., Numanoglu, H.M., Civalek, O., Bending Response of Nanobeams Resting on Elastic Foundation. Journal of Applied and Computational Mechanics, 4(2), 105-114, 2018.

[3] Mercan, K., Civalek, O., DSC method for buckling analysis of boron nitride nanotube (BNNT) surrounded by an elastic matrix. Composite Structures, 143, 300-309, 2016.

[4] Mercan, K., Civalek, Ö., Buckling analysis of Silicon carbide nanotubes (SiCNTs) with surface effect and nonlocal elasticity using the method of HDQ. Composites Part B: Engineering, 114, 34-45, 2017.

[5] Numanoglu, H.M., Mercan, K., Civalek, O., Finite element model and size-dependent stability analysis of boron nitride and silicon carbide nanowires/nanotubes. Scientia Iranica, 26(4), 2079-2099, 2019.

[6] Ferreira, T.H., Faria, J.A.Q.A., Gonzalez, I.J., Outon, L.E.F., Macedo, W.A.A., Gomes, D.A., Sousa, E.M.B., BNNT/Fe3O4 System as an Efficient Tool for Magnetohyperthermia Therapy. Journal of Nanoscience and Nanotechnology, 18(10), 6746-6755, 2018.

[7] Khaleghian, M., Azarakhshi, F., Quantum Mechanical Investigation of Geometrical Structure and Dynamic Behavior of h-BNNT $(9,9-5)$ and h-AINNT $(9,9-5)$ Single-Walled Nanotubes: NBO Analysis. Letters in Organic Chemistry, 16(9), 705-717, 2019. 
[8] Vedaei, S.S., Nadimi, E., Gas sensing properties of CNT-BNNT-CNT nanostructures: A first principles study. Applied Surface Science, 470, 933-942, 2019.

[9] Ashraf, M.A., Liu, Z., Najafi, M., DFT Study of CN Oxidation $(\mathrm{CN}+1 / 2 \mathrm{O}(2)->\mathrm{OCN})$ on the Surfaces of Chromium-Doped Nanotubes $(\mathrm{Cr}-\mathrm{CNT}(8,0)$ and Cr-BNNT $(8,0))$. Russian Journal of Physical Chemistry B, 14(2), 217-221, 2020.

[10] Li, Y., Chen, P.J., Zhang, C., Peng, J., Gao, F., Liu, H., Molecular dynamics simulation on the buckling of single-layer MoS2 sheet with defects under uniaxial compression. Computational Materials Science, 162, 116-123, 2019.

[11] Yang, B., Li, M.D., Wang, J.Y., Zhang, J.C., Liao, D.M., Yue, Y.N., Critical fracture properties of puckered and buckled arsenenes by molecular dynamics simulations. Physical Chemistry Chemical Physics, 21(23), 12372-12379, 2019.

[12] Jiang, S.P., Wu, H.L., Kou, L.Z., Tang, C., Wang, C.Y., Chen, C.F., Buckling of blue phosphorus nanotubes under axial compression: Insights from molecular dynamics simulations. Journal of Applied Physics, 127(1), 2020.

[13] Ajori, S., Boroushak, S.H., Hassani, R., Ansari, R., A molecular dynamics study on the buckling behavior of $\mathrm{x}$-graphyne based single- and multi-walled nanotubes. Computational Materials Science, 191, 2021.

[14] Zhang, J., Zhou, J.L., Buckling of boron nanotubes under axial compression: Insights from molecular mechanics and continuum mechanics. Physica E-Low-Dimensional Systems \& Nanostructures, 127, 2021.

[15] Mercan, K., Emsen, E., Civalek, O., Effect of silicon dioxide substrate on buckling behavior of Zinc Oxide nanotubes via size-dependent continuum theories. Composite Structures, 218, 130-141, 2019.

[16] Arefi, M., Firouzeh, S., Bidgoli, E.M.R., Civalek, O., Analysis of porous micro -plates reinforced with FG-GNPs based on Reddy plate theory. Composite Structures, 247, 2020.

[17] Dastjerdi, S., Akgoz, B., Civalek, O., On the effect of viscoelasticity on behavior of gyroscopes. International Journal of Engineering Science, 149, 2020.

[18] Yayli, M.Ö., Torsional vibration analysis of nanorods with elastic torsional restraints using non-local elasticity theory. Micro \& Nano Letters, 13(5), 595-599, 2018.

[19] Yayli, M.O., Cercevik, A.E., Axial vibration analysis of cracked nanorods with arbitrary boundary conditions. Journal of Vibroengineering, 17(6), 2907-2921, 2015.

[20] Civalek, O., Uzun, B., Yayli, M.O., Stability analysis of nanobeams placed in electromagnetic field using a finite element method. Arabian Journal of Geosciences, 13(21), 2020. 
[21] Uzun, B., Yaylı, M.Ö., Nonlocal vibration analysis of Ti-6Al-4V/ZrO2 functionally graded nanobeam on elastic matrix. Arabian Journal of Geosciences, 13(4), 155, 2020.

[22] Uzun, B., Yayli, M.O., Deliktas, B., Free vibration of FG nanobeam using a finite-element method. Micro \& Nano Letters, 15(1), 35-40, 2020.

[23] Mercan, K., Numanoglu, H.M., Akgoz, B., Demir, C., Civalek, O., Higher-order continuum theories for buckling response of silicon carbide nanowires (SiCNWs) on elastic matrix. Archive of Applied Mechanics, 87(11), 1797-1814, 2017.

[24] Civalek, Ö., Kiracioglu, O., Free vibration analysis of Timoshenko beams by DSC method. International Journal for Numerical Methods in Biomedical Engineering, 26(12), 1890$1898,2010$.

[25] Demir, C., Mercan, K., Civalek, O., Determination of critical buckling loads of isotropic, FGM and laminated truncated conical panel. Composites Part B-Engineering, 94, 1-10, 2016.

[26] Ersoy, H., Mercan, K., Civalek, O., Frequencies of FGM shells and annular plates by the methods of discrete singular convolution and differential quadrature methods. Composite Structures, 183, 7-20, 2018.

[27] Mercan, K., Baltacioglu, A.K., Civalek, O., Free vibration of laminated and FGM/CNT composites annular thick plates with shear deformation by discrete singular convolution method. Composite Structures, 186, 139-153, 2018.

[28] Mercan, K., Ebrahimi, F., Civalek, O., Vibration of angle-ply laminated composite circular and annular plates. Steel and Composite Structures, 34(1), 141-154, 2020.

[29] Mercan, K., Demir, Ç., Civalek, Ö., Vibration analysis of FG cylindrical shells with powerlaw index using discrete singular convolution technique. Curved and Layered Structures, 3(1), 2016.

[30] Hadji, L., Avcar, M., Civalek, Ö., An analytical solution for the free vibration of FG nanoplates. Journal of the Brazilian Society of Mechanical Sciences and Engineering, 43(9), 418, 2021.

[31] Civalek, O., Avcar, M., Free vibration and buckling analyses of CNT reinforced laminated non-rectangular plates by discrete singular convolution method. Engineering with Computers, 2020.

[32] Avcar, M., Hadji, L., Civalek, Ö., Natural frequency analysis of sigmoid functionally graded sandwich beams in the framework of high order shear deformation theory. Composite Structures, 276, 114564, 2021. 
[33] Hadji, L., Avcar, M., Nonlocal free vibration analysis of porous FG nanobeams using hyperbolic shear deformation beam theory. Advances in Nano Research, 10(3), 281-293, 2021.

[34] Rubio, A., Corkill, J.L., Cohen, M.L., Theory of graphitic boron nitride nanotubes. Physical Review B, 49(7), 5081-5084, 1994.

[35] Eringen, A.C., On Differential-Equations of Nonlocal Elasticity and Solutions of Screw Dislocation and Surface-Waves. Journal of Applied Physics, 54(9), 4703-4710, 1983.

[36] Asghari, M., Kahrobaiyan, M.H., Ahmadian, M.T., A nonlinear Timoshenko beam formulation based on the modified couple stress theory. International Journal of Engineering Science, 48(12), 1749-1761, 2010.

[37] Akbas, S.D., Mercan, K., Civalek, O., Post-buckling analysis of aorta artery under axial compression loads. Advances in Nano Research, 8(3), 255-264, 2020.

[38] Uzun, B., Civalek, Ö., Yayl1, M.Ö., Vibration of FG nano-sized beams embedded in Winkler elastic foundation and with various boundary conditions. Mechanics Based Design of Structures and Machines, 1-20, 2020.

[39] Demir, C., Akgoz, B., Erdinc, M.C., Mercan, K., Civalek, O., Free vibration analysis of graphene sheets on elastic matrix. Journal of the Faculty of Engineering and Architecture of Gazi University, 32(2), 551-562, 2017.

[40] Thompson, A.P., Aktulga, H.M., Berger, R., Bolintineanu, D.S., Brown, W.M., Crozier, P.S., in 't Veld, P.J., Kohlmeyer, A., Moore, S.G., Nguyen, T.D., Shan, R., Stevens, M.J., Tranchida, J., Trott, C., Plimpton, S.J., LAMMPS - a flexible simulation tool for particlebased materials modeling at the atomic, meso, and continuum scales. Computer Physics Communications, 271, 108171, 2022.

[41] Sevik, C., Kinaci, A., Haskins, J.B., Cagin, T., Characterization of thermal transport in low-dimensional boron nitride nanostructures. Physical Review B, 84(8), 2011.

[42] Tersoff, J., Modeling solid-state chemistry: Interatomic potentials for multicomponent systems. Physical Review B, 39(8), 5566-5568, 1989.

[43] Zeighampour, H., Beni, Y., Electromechanical buckling analysis of boron nitride nanotube using molecular dynamic simulation. Chinese Journal of Physics, 67, 212-221, 2020.

[44] Zeighampour, H., Beni, Y.T., Buckling analysis of boron nitride nanotube with and without defect using molecular dynamic simulation. Molecular Simulation, 46(4), 279-288, 2020.

[45] Mercan, K., Demir, Ç., Akgöz, B., Civalek, Ö., Coordinate Transformation for Sector and Annular Sector Shaped Graphene Sheets on Silicone Matrix, International Journal of Engineering and Applied Sciences, 7(2), 56-73, 2015. 
[46] Mercan, K. , Civalek, Ö., Buckling Analysis of Silicon Carbide Nanotubes (SiCNTs), International Journal of Engineering and Applied Sciences, 8(2), 101-108, 2016.

[47] Emsen, E., Mercan, K., Akgöz, B., Civalek, Ö., Modal analysis of tapered beam-column embedded in winkler elastic foundation, International Journal of Engineering and Applied Sciences, 7(1), 1-11, 2015.

[48] Akgöz, B. , Mercan, K. , Demir, Ç., Civalek, Ö., Static Analysis of Beams on Elastic Foundation by the Method of Discrete Singular Convolution, International Journal of Engineering and Applied Sciences, 8(3), 67-73, 2016.

[49] Mercan, K., Akgöz, B., Demir, Ç., Civalek, Ö., Frequencies Values of Orthotropic Composite Circular and Annular Plates, International Journal of Engineering and Applied Sciences, 9(2), 55-65, 2017.

[50] Numanoglu, H.M. , Mercan, K., Civalek, Ö., Frequency and Mode Shapes of Au Nanowires Using the Continuous Beam Models, International Journal of Engineering and Applied Sciences, 9 (1) , 55-61, 2017.

[51] Civalek, O., Numanoglu, H.M., Mercan, K., Finite Element Model and Size Dependent Stability Analysis of Boron Nitride and Silicon Carbide Nanowires/Nanotubes, Scientia Iranica, 26(Issue 4: Special Issue Dedicated to Professor Abolhassan Vafai), 2079-2099. 2019.

[52] Mercan, K., A Comparative Buckling Analysis of Silicon Carbide Nanotube and Boron Nitride Nanotube, International Journal of Engineering and Applied Sciences, 8(4), 99$107,2016$.

[53] Mercan, K., Demir, Ç., Ersoy, H., Civalek, Ö., The effects of thickness on frequency values for rotating circular shells, International Journal of Engineering and Applied Sciences, 8(1), 26-37, 2016.

[54] Mercan, K., Civalek, Ö., Modal Analysis of Micro and Nanowires Using Finite Element Softwares, International Journal of Engineering and Applied Sciences, 10(4), 291-304, 2019.

[55] Mercan, K., Civalek, Ö., Comparison of small scale effect theories for buckling analysis of nanobeams, International Journal of Engineering and Applied Sciences, 9(3) , 87-97, 2017.

[56] Mercan, K., Aydoğdu, İ., Civalek, Ö., Discrete Singular Convolution and Differential Quadrature Method for Buckling Analysis of Laminated Composite Plates, International Journal of Engineering and Applied Sciences , 8(4) , 66-74, 2016. 